\title{
Desvendando a queixa escolar: um estudo no Serviço de Psicologia da Universidade Federal de Rondônia
}

\author{
Desvendando a queixa escolar
}

\author{
Mariana Sathie Nakamura \\ Vanessa Aparecida Alves de Lima \\ Iracema Neno Cecilio Tada \\ Maria Hercília Rodrigues Junqueira
}

\begin{abstract}
Resumo
$\mathrm{Na}$ história da psicologia escolar, a compreensão dos processos de produção e acompanhamento da queixa escolar é essencial, pois revelam a forma como a educação é percebida e construída pelos diversos atores do cenário educacional. Nesta perspectiva, procura-se conhecer a queixa escolar na cidade de Porto Velho (RO), por meio dos prontuários do Serviço de Psicologia Aplicada (SPA) da Universidade Federal de Rondônia (UNIR). Foram analisados 634 prontuários, entre os anos de 1993 e 2006. Os prontuários foram analisados pela categorização de Souza (1997), acrescentando uma categoria (causa apontada pelos familiares). Os resultados corroboram pesquisas nacionais de mesmo cunho, onde a queixa escolar sofre um processo de patologização, psicologização e medicalização, bem como recebe atendimento na clínica-escola onde não se consideram os diversos atores da produção do fracasso escolar, nomeando o aluno e seus familiares pelos problemas constitucionais e emocionais.
\end{abstract}

Palavras-chave: Problemas escolares, Psicologia escolar, Prontuários.

\section{Revealing the school complaint: a study in the Service of Applied Psychology (SPA) of the Federal University of Rondônia}

\begin{abstract}
In the history of the school psychology, the understanding of the production processes and attendance of the school complaint is essential, because they reveal the form as the education is noticed and built by the several actors of the education scenery. In this perspective, we tried to get to know the school complaint in the city of Porto Velho (RO), by the records of the Service of Applied Psychology (SPA) of the Federal University of Rondônia (UNIR). 634 records were analyzed, between the years of 1993 and 2006. The records were analyzed by Souza's categorization (1997), increasing a category (causes pointed by the relatives). The results corroborate national researches of same stamp, where the school complaint suffers a medical, psychological and pathological process, as well as they receives service at the clinic-school that they don't consider the several actors of the production of the school failure, naming the students and their relatives by constitutional and emotional problems.
\end{abstract}

Keywords: School problems, School psychology, Client records.

\section{Desvendando la queja escolar: un estudio en el servicio de Psicología de la Universidad Federal de Rondônia}

\section{Resumen}

En la historia de la psicología escolar, la comprensión de los procesos de producción y acompañamiento de la queja escolar es esencial, pues muestran como es percibida la educación y construida por los diversos actores del escenario educacional. En esta perspectiva, se busca conocer la queja escolar en la ciudad de Porto Velho (RO), por medio de los prontuarios del Servicio de Psicología Aplicada (SPA) de la Universidad Federal de Rondônia (UNIR). Fueron analizados 634 prontuarios entre los años de 1993 y 2006. Los prontuarios fueron analizados por la categorización de Souza (1997), aumentando una categoría (causa indicada por los familiares). Los resultados corroboran investigaciones nacionales del mismo tipo, donde la queja escolar sufre un proceso de patologización, psicologización y medicalización, así como también es atendida en la clínica-escuela, donde no se consideran los diversos actores de la producción del fracaso escolar, nombrando el alumno y sus familiares por los problemas constitucionales y emocionales.

Palabras clave: Problemas escolares, Psicología escolar, Prontuarios. 


\section{Introdução}

A Psicologia Escolar é uma área de atuação da ciência psicológica bastante recente e que vem sofrendo profundas transformações na maneira de atuar. Nesta perspectiva, a compreensão da Queixa Escolar é um aspecto essencial que revela, desde sua compreensão até a forma de atendimento e acompanhamento, as transformações teóricas e críticas sofridas nesta área.

O processo histórico de construção da queixa escolar vem sendo explicado segundo Patto (1997a) e Collares e Moysés (1996), em termos biopsicológicos e de carência cultural, sendo o aluno e seus familiares culpabilizados pelo insucesso escolar.

De acordo com Azevedo (2000), o psicólogo escolar busca uma atuação clínica na escola, decorrência das expectativas da própria escola por este tipo de atendimento individualizado, que solucione "o maior número de problema dos alunos num curto espaço de tempo" (p.12), por meio da aplicação de testes psicológicos. Esta forma de avaliação tende a ser psicologizante e patologizante da queixa escolar (Machado, 2000; Proença, 2000), contribuindo para culpabilizar o próprio aluno ou a sua família pelo fracasso escolar em detrimento da compreensão das relações constituídas no contexto escolar.

Patto (1997b), já alertava para que a psicologia escolar se preocupasse com a estrutura social, ideológica e histórica da educação, inseridas "num país capitalista dependente, que fundamenta uma visão crítica da escola enquanto instituição social que reproduz em seu interior o estado de coisa em vigor na sociedade que a inclui" (p.467).

Para Souza (1996; 2007), o atendimento clínico da queixa escolar é explicado em termos do enfoque clínico na formação do futuro profissional da Psicologia, com os cursos de graduação priorizando disciplinas de testes e de psicoterapias em detrimento do enfoque institucional.

Para compreender o que acontecia com o aluno tido como problema ou multirepetente, Machado (2000) e Meira (2000) postulam ser necessária uma análise históricocrítica da situação escolar e das diversas versões sobre o encaminhamento para o psicólogo, considerando as vozes do próprio aluno, de sua família e da escola.

A preocupação em apresentar novas formas de atuação, que visavam modificar o modelo clínico e o uso indevido de testes psicológicos, pode ser verificada, por exemplo, nos trabalhos de Collares e Moysés (1996), Freller (2004); Machado (2000; 2004); Meira (2000); Patto (2005); Sayão e Guarido (2004) e Souza (2006). Seus relatos estão fundamentados em uma prática que busca conhecer a criança encaminhada, para além dos rótulos que a têm definido.
A pesquisa realizada por Collares e Moysés (1996) representou um marco na compreensão da queixa escolar, porque confrontou a visão de gestores, professores, pais, alunos e profissionais da saúde, que são, historicamente, aqueles a quem tem sido atribuída a responsabilidade de referendar o diagnóstico construído pela escola.

Freller (2004); Machado (2004); Sayão e Guarido (2004) e Souza (2006) entre outros, propõem uma intervenção no ambiente escolar que, diferentemente da atuação clínica, busquem uma ação coletiva dos vários atores escolares, por meio da observação participante, diálogos informais para que o psicólogo escolar possa realmente ouvir as vozes de todos os envolvidos no processo de escolarização, alunos, familiares, professores, equipe técnica e de apoio, bem como os gestores, contribuindo para que o psicólogo se aproprie do cotidiano escolar.

Tendo como objetivo compreender a presença dos processos acima descritos no sistema educacional de Porto Velho $(\mathrm{RO})$, seguindo as perspectivas de análise de Souza (1996; 1997), analisaram-se os prontuários dos alunos encaminhados com queixa escolar para o Serviço de Psicologia Aplicada da Universidade Federal de Rondônia (UNIR), tendo como questões norteadoras: a) o que existe por trás destas queixas? b) como o nosso serviço tem atendido estas queixas? c) que mudanças podem ser observadas na construção da queixa escolar considerando os treze anos de existência de nosso serviço?

Buscou-se contribuir para desvelar os tipos de queixa escolar mais freqüentes no município de Porto Velho/Rondônia, possibilitando orientação mais adequada aos estagiários de Psicologia Escolar desta Universidade, além de ter como intenção, viabilizar melhor atendimento à população assistida no Serviço de Psicologia da UNIR.

Entendeu-se que os resultados apresentados contribuem para uma compreensão da queixa escolar também no cenário nacional, considerando os aspectos sociais, políticos e educacionais. Os resultados poderão ser utilizados para nortear ações escolares, que busquem diminuir o número de crianças diagnosticadas como "problema" para a escola.

\section{Método}

\section{Local}

A pesquisa foi realizada no Serviço de Psicologia Aplicada - SPA, do curso de Psicologia, da Universidade Federal de Rondônia - UNIR, localizada no centro da cidade de Porto Velho. O SPA oferece suporte aos alunos do $9^{\circ}$ e $10^{\circ}$ períodos do curso de Psicologia, que realizam atendimento supervisionado à comunidade e objetiva à 
conscientização das atribuições do profissional psicólogo, bem como, sua preparação para o mercado de trabalho.

\section{Material}

Foram lidas um total de 3.821 fichas de triagem compreendendo os anos de 1996 a 2006. Destas, 1.839 são de crianças e adolescentes de até 18 anos, sendo 634 encaminhadas com queixa escolar. A maioria refere-se a pacientes do sexo masculino $(77 \%$ dos pacientes com queixa escolar) entre a faixa etária de 5 a 9 anos (48\%), estudantes em escola pública $(91 \%)$ cursando a $1^{\text {a }}$ série do ensino fundamental (22\%), com renda familiar de 1 a 2 salários mínimos (37\%), embora esse número pudesse ser outro devido a muitas fichas, especialmente de 1996 a 1998 não solicitarem este dado.

\section{Procedimento}

A análise das queixas escolares foi realizada quantitativa e qualitativamente, de maneira a permitir uma detalhada descrição dos dados, respeitando a maneira como foram registrados, além de possibilitar a compreensão do processo da questão investigada (Bogdan \& Biklen, 1994).

Dentre as técnicas de pesquisas qualitativas optou-se pela documental, por ser uma técnica valiosa para a obtenção das informações contidas nas fichas de triagem e de atendimento, objeto de estudo do presente trabalho (Alves-Mazzotti \& Gewandsznajder, 2000).

A verificação das fichas tornou possível perceber a semelhança com os dados apresentados por Souza (1997), a respeito dos motivos que levaram as crianças com queixa escolar a procurar acompanhamento psicológico. Portanto, optou-se por utilizar a categorização desenvolvida pela autora para agrupá-los. Desta forma, foram utilizadas as seguintes categorias: problemas de aprendizagem - problema na leitura e escrita, quantificação, problemas de aprendizagem vagamente descritos em que não são oferecidas informações suficientes para a análise, problemas referentes ao ritmo de aprendizagem - por não acompanhar os conteúdos ou os colegas, história de repetência e problemas com a lição de casa; problemas de atitude, que são relativos à desobediência das regras da sala de aula, agressividade, timidez, comportamento infantil ou imaturo, desatenção e desinteresse pelas tarefas, nervosismo e irritação - por medo de errar ou por difícil socialização; problemas de relacionamento da criança em relação ao professor ou do professor em relação à criança; outros problemas relacionados à aprendizagem, em que os pais não acreditam que haja algum problema de aprendizagem com seu filho e solicitação específica para avaliação psicológica. No decorrer da leitura das fichas de triagem, foi necessária a criação de outra categoria, a de causa levantada pelo informante, que compreende principalmente a desestruturação familiar, presente em alguns relatos que relacionam a queixa escolar ao fato de os pais serem separados ou de a criança morar na companhia de outros familiares, problemas de saúde, doenças ou distúrbios neurológicos e dificuldades sensoriais, como a necessidade de usar óculos.

A partir da análise dos prontuários e após gerar a lista de categorias, optou-se pela visualização por meio de um Diagrama de Setores para demonstrar os motivos que levaram à busca do SPA/UNIR para atendimento, fazendo uma distribuição de freqüência a partir das orientações e conceitos de Kazmier (1982).

\section{Resultados e Discussão}

\section{Algumas considerações acerca dos prontuários}

No período de 1993 a 1995 não há registro de qualquer relato que pudesse caracterizar a busca de atendimento psicológico devido à queixa escolar, em função do modelo de ficha que continha apenas dados pessoais, como nome, endereço e idade.

De 1996 a 1997 os prontuários passaram a apresentar novos modelos de fichas de registro, contemplando informações dos motivos que levaram à procura de atendimento enfocando, no caso de crianças e adolescentes, informações referentes à gravidez, à infância, ao desenvolvimento neuro-psico-motor, medicamentos utilizados, percurso médico; informações relacionadas ao cotidiano familiar. Este modelo de atendimento mostra o enfoque clínico dado à queixa escolar, buscando a psicologização e a patologização desta, como discutido por Collares e Moysés (1996) e Souza (1996; 2007), desconsiderando o processo de escolarização e desconhecendo o contexto escolar local de construção desta queixa (Freller, 2004; Machado, 2004; Sayão \& Guarido, 2004).

A partir de 1998 até a época da pesquisa, um novo modelo de ficha foi adotado, dando ênfase à queixa do cliente, com base na fala dos familiares e do próprio aluno encaminhado.

\section{Análise dos Prontuários}

As fichas de triagem analisadas totalizam $231 \mathrm{em} 1996$, 230 em 1997, 189 em 1998, 344 em 1999, 583 em 2000, 345 em 2001, 425 em 2002, 446 em 2003, 618 em 2004, 211 em 2005 e 209 em 2006. A quantidade de fichas segundo os anos se refere à oferta de estágios no Curso de Psicologia da UNIR, que variou de acordo com a disponibilidade do professor-supervisor e a quantidade de alunos interessados em cada área de estágio oferecido, pois estas fichas referem-se aos clientes que foram 
efetivamente atendidos e não toda a demanda em espera no SPA/UNIR.

Em relação ao atendimento a jovens e adolescentes, em 2004 chega compreender $52 \%$ dos atendimentos, sendo sempre significativo em todos os anos. O número de atendimento a queixa escolar também é relevante, visto que em 1997 totaliza 83, chegando a 108 em 2004, representando, neste ano, $24 \%$ do total dos atendimentos.

Foi constatado também, que grande parte dos atendimentos se refere a meninos de idades entre 05 e 14 anos, cursando os primeiros anos do ensino fundamental, na rede pública de ensino, cuja renda familiar, em sua maioria, compreende um salário mínimo.

Do total de prontuários analisados, $77 \%$ da clientela com queixa escolar era composta de meninos e apenas $23 \%$ de meninas, na faixa etária de 5 a 14 anos (48\% entre
5 e 9 anos), cursando os primeiros anos do ensino fundamental ( $22 \%$ na $1^{1}$ a série) na rede pública ( $91 \%$ e, em sua maioria, com renda familiar de um salário mínimo.

Em vários prontuários havia mais de uma queixa apresentada pelos acompanhantes na procura de atendimento no SPA-UNIR, entre 1996 e 2006, por isto o número de queixas escolares supera o total de prontuários analisados.

Em nosso estudo, a categoria com maior incidência de queixa foi a de problemas de aprendizagem e de atitude, o que Collares e Moysés (1996) classificam como estigmatização. Os alunos são rotulados como doentes, preguiçosos ou desmotivados e, a partir de então, começa a busca por tratamento, sem considerações a respeito das relações existentes no ambiente escolar.

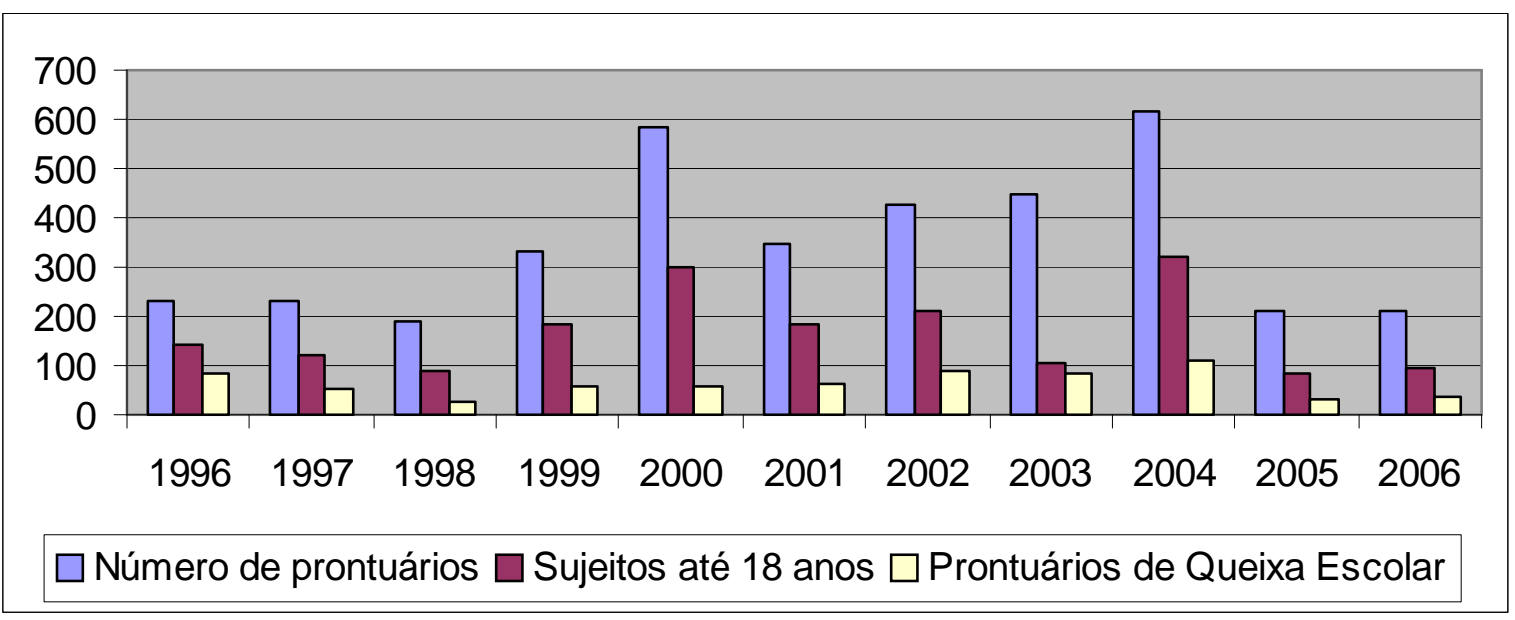

Figura 1. Prontuários de 1996 a 2006 do SPA/UNIR segundo faixa etária e queixa escolar.

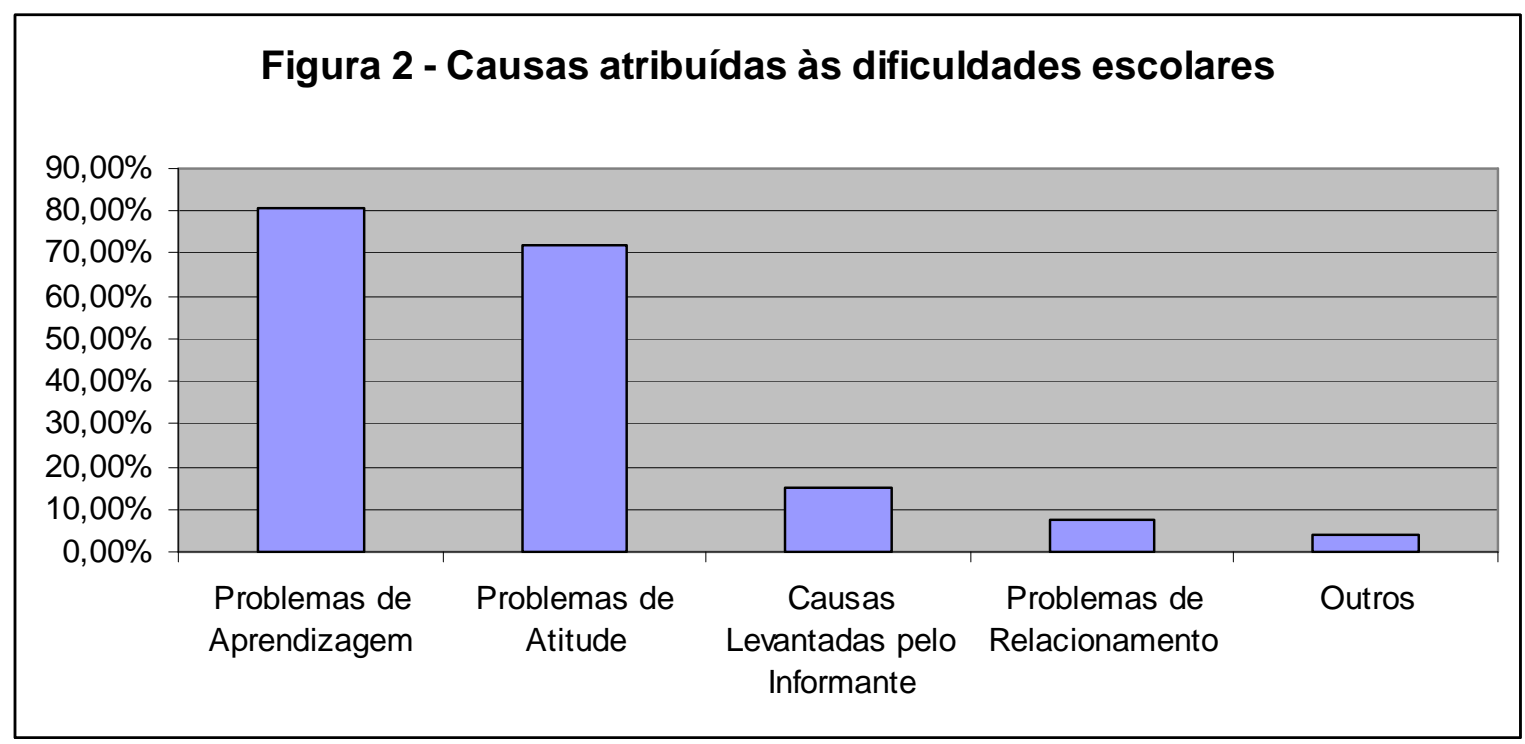

Figura 2. Causas atribuídas às dificuldades escolares. 
Entretanto, o próprio uso destas categorias tende a enfatizar as deficiências centradas na criança, pois é ela quem não consegue ler ou escrever, é ela quem fica nervosa e, conseqüentemente, não consegue responder às tarefas. Embora o fracasso escolar possa ser entendido como resultado das relações escolares, pouco parece ser refletido sobre o tema.

Revelam-se, então, os mecanismos que são criados para propagar os mitos presentes na realidade escolar. $O$ primeiro deles diz respeito à própria criança, claramente visto na forma como a maioria das queixas são apresentadas, o segundo, à sua família, e o terceiro, aos professores (Collares \& Moysés, 1996). Em momentos diferentes, a culpa pelo insucesso escolar recai sobre um desses atores escolares.

Em relação aos professores, poucos dados foram coletados nos prontuários e, a maioria deles, diz respeito ora, aos esforços do professor em auxiliar o aluno ora, em controlá-lo, uma vez que ele pode apresentar problemas de atitude ou relacionamento.

$\mathrm{Na}$ fala dos acompanhantes, percebe-se certa insegurança e a impressão de como se originou a dificuldade escolar (causa levantada pelo informante). Não são raros os casos em que os próprios se culpam pelo fato, que segundo Souza (1997, p. 24), é comum ao analisar que "Muitos pais [...] ao serem argüidos pelo psicólogo a respeito dos motivos do encaminhamento procuram encontrar suas causas na história de vida não raro se culpando por muitos desses acontecimentos." Nesta pesquisa surgiram explicações como quedas, acidente de carro ou doenças como meningite. Se o ambiente familiar for conturbado, com brigas entre os pais, pais separados, ou crianças que moram com outros parentes (tios, avós), é levado em consideração. Aspectos como alcoolismo e agressões, também são considerados.

Torna-se evidente a existência do mito de que famílias desestruturadas tendem a gerar crianças desajustadas (Collares \& Moysés, 1996). Porém, o que classifica uma família como "problemática" ainda não foi definido, o que se encontra são indicações de que os pais se culpam por não darem a devida atenção aos filhos, não os acompanhando na execução das lições de casa.

O que se percebe é um processo de escolarização em que se tem muita dificuldade em ensinar e não se sabe como lidar pedagogicamente com questões ligadas ao processo de escolarização (Souza, 1996), bem como não se busca maior integração e reflexão entre pais, escola e alunos para compreender o processo da produção do fracasso escolar.

\section{Atendimentos Realizados}

Os atendimentos referentes à queixa escolar foram realizados, no decorrer dos anos de 1996 a 2005 de duas maneiras, em psicopedagogia (em que se oferece acompanhamento psicopedagógico e psicodiagnóstico) e em ludoterapia (em grupo ou individual, baseados na Abordagem Centrada na Pessoa, desenvolvida por Carl Rogers). Em 2006, os alunos com queixa escolar foram atendidos em ludoterapia e em Psicologia Escolar com intervenção crítica, como discutida por Machado (2000; 2004); Meira (2000); Patto (2005); Sayão e Guarido (2004) e Souza (2006). Neste ano, o estágio em psicopedagogia não foi oferecido devido à docente encontrar-se afastada para realizar seu doutorado.

No atendimento psicopedagógico houve uma busca do psicodiagnóstico por meio de testes psicométricos, de personalidade e de provas piagetianas. $O$ relato de atendimento se refere basicamente ao que foi constatado na criança, se a queixa foi confirmada e quais atitudes foram tomadas para melhorar o comportamento do paciente.

A prática do psicodiagnóstico é vista por Marçal e Silva (2006, p. 124) como uma "tentativa de verificar o que existe 'por trás' da queixa, e detectar se é um problema de ordem emocional ou uma questão escolar". Assim há uma cisão entre o problema emocional e o escolar, não se compreendendo a ligação entre as duas situações, tendo como instrumentos: anamnese, hora lúdica, desenho, HTP, CAT, Bender, observação da criança e na relação com a família (atendimento conjunto), observação da leitura e da escrita da criança e observação do caderno. Os atendimentos são feitos em grupos de crianças e em grupos de orientação a pais. A temática do grupo de pais centra a discussão nas crianças e suas famílias e "não possibilitam discussões que abordem o papel social da escola na constituição da queixa" (Marçal \& Silva, 2006, p. 126).

Outra questão a ser considerada no atendimento psicopedagógico do SPA é que o problema escolar não é referenciado, uma vez que os profissionais não se dirigem à escola para conversar com os demais atores do cotidiano escolar e procurar compreender quais as condições da situação e local da queixa.

Esta pesquisa corrobora os resultados encontrados por Marçal e Silva (2006) e por Souza (1996) que apontam para o fato de que os cursos de formação de psicólogos não estão instrumentalizando os profissionais da psicologia para lidar com a demanda e a problemática da produção das queixas escolares.

Em relação à ludoterapia, o atendimento é igualmente centrado na criança e busca modificar os comportamentos que originaram a queixa, na maioria dos casos, caracterizados por serem agressivos ou excessivamente tímidos. E mais uma vez, esse tipo de procedimento tende a reforçar a culpa do insucesso escolar na criança.

Com relação ao estágio supervisionado em Psicologia Escolar, não se encontrou prontuários registro dos atendimentos. 
Os prontuários analisados não são suficientemente descritivos e assim, ficou-se sem ter uma clara noção do real papel do SPA e da sua contribuição substancial para a melhoria da compreensão dos problemas educacionais como um processo histórico que se produz em múltiplas interações sociais do contexto em que se insere (Neves \& Marinho-Araújo, 2006).

Por fim, observou-se o grande número de anotações de casos que não receberam atendimento porque não foram localizados ou por abandono do atendido. Este dado também é encontrado em outros estudos, onde a busca da compreensão de tal situação se dá pela problematização da inadequação do atendimento psicológico clássico para as populações de baixa renda "e, dessa forma, mais vezes, os pacientes são responsabilizados e não a prática psicológica que Ihes é proposta" (Neves \& Marinho-Araújo, 2006, p. 166).

\section{Considerações finais}

Os dados apontam na direção indiscutível de que é necessário que 0 aluno encaminhado com queixa escolar ao atendimento psicológico do SPA da UNIR seja visto como um ser cujas relações na escola também são importantes de serem consideradas, e não de maneira a culpabilizar o aluno e/ou sua família pelo fracasso escolar como vinha ocorrendo até o ano de 2005, quando não se oferecia o estágio de Psicologia Escolar.

Vale ressaltar que a prática psicologizante frente a queixa escolar é ainda uma prática comum em algumas clínicas-escolas como verificado por Souza (1996), em decorrência de uma formação pautada na Psicologia Clínica e psicométrica.

No SPA/UNIR é considerável o número de crianças e adolescentes cujo motivo da procura é problema escolar. Nesta pesquisa pode-se constatar que, nos anos de 1996 a 2006, muitas semelhanças com os relatos de Machado (2000) e Souza (1996; 1997), no que tange à maneira como a queixa escolar usualmente é apresentada nos prontuários e como é atendida. São relatos de pais que julgam seus filhos por suas incapacidades e de profissionais que, de certa forma, não estão preparados para compreender o processo da construção da queixa escolar em toda a sua amplitude.

Infelizmente a presente pesquisa constata a triste realidade do sistema educacional brasileiro, que vem reproduzindo segregação e opressão, onde os interesses políticos e econômicos são mais relevantes que o valor da pessoa. O SPA/UNIR, bem como as instituições de saúde e de educação que encaminharam as crianças para esta clínica-escola, arcam com a responsabilidade de solucionar situações sociais graves, que necessitam de atitudes amplas e contextualizadas. Assim, de acordo com
Neves e Marinho-Araújo (2006), que percebem que os fracassos evidenciados pelo aluno por meio das dificuldades de aprendizagem refletem na verdade 0 "fracasso da escola, enquanto sistema social responsável pela aquisição e transmissão do conhecimento" (2006, p. 162).

Está claro na leitura dos prontuários, assim como na análise de Neves e Marinho-Araújo (2006) sobre as dificuldades de aprendizagem, que falta aos estagiários em atendimento no SPA uma perspectiva integrada da dinamicidade dos fatores que produzem as dificuldades de aprendizagem, embora esta abordagem possa ser encontrada nos diversos autores que estudam a problemática, como por exemplo, Bock (2003), Patto (1997b); Souza (1996), Tanamachi (2000) entre outros.

Frente aos dados desta pesquisa questiona-se o que falta para a melhoria da compreensão do serviço de atendimento às queixas escolares no SPA/UNIR. Acreditase que, corroborando os estudos realizados por Meira (2000); Proença (2000); Tanamachi (2000), entre outros, ainda há uma grande defasagem na formação do psicólogo brasileiro, sendo necessária maior ênfase nas questões sociais e educacionais. Também se entende que um procedimento de discussão entre os estagiários que trabalham com queixas escolares possa contribuir para perceberem o problema como social e historicamente produzido, e não como um processo isolado e individual, que careça de tratamento emocional, apenas.

Quanto à formação dos psicólogos, o Curso de Psicologia da UNIR tem discutido uma nova proposta de Matriz Curricular que inclui, como uma ênfase curricular, a Psicologia Escolar, que se entende ser uma boa perspectiva para uma compreensão mais ampla da problemática que envolve as dificuldades de aprendizagem.

Em 2006 aconteceu o primeiro estágio supervisionado em Psicologia Escolar, fundamentado na teoria histórico crítica social da compreensão do fracasso escolar. No entanto, não foram encontrados nos prontuários de atendimento qualquer referência que anuncie como o estagiário desenvolveu o processo de compreensão das queixas escolares encaminhadas para o SPA. Sugere-se, portanto, que além dos relatórios de estágio, o acompanhamento fique registrado nos prontuários do SPA, assim como as demais áreas.

Espera-se que esta pesquisa venha proporcionar maior reflexão sobre o entendimento da queixa escolar e sobre os procedimentos tomados diante dela, de forma a buscar melhorias em seu atendimento.

\section{Referências}


Alves-Mazzotti, A. J., \& Gewandsznajder, F. (2000). O método nas ciências naturais e sociais: pesquisa quantitativa e qualitativa. São Paulo: Pioneira.

Azevedo, A. C. P. (2000). Psicologia escolar: o desafio do estágio. Lorena, SP: Stiliano.

Bogdan, R., \& Biklen, S. (1994). Investigação qualitativa educação.

Portugal:

Porto.

Collares, C. A. L., \& Moysés, M. A. A. (1996). Preconceitos no cotidiano escolar: ensino e medicalização. São Paulo: Cortez.

Freller, C. C. (2004). Grupos de crianças com queixa escolar: um estudo de caso. Em M. P. R. Souza \& A. M. Machado (Orgs.), Psicologia escolar: em busca de novos rumos (pp. 127-141). São Paulo: Casa do Psicólogo.

Kazmier, L. J. (1982). Estatística aplicada à administração e economia. São Paulo: MacGraw-Hill do Brasil.

Machado, A. M. (2000). Avaliação psicológica na educação: mudanças necessárias. Em E. Tanamachi, M. Proença \& M. Rocha (Org.), Psicologia e educação: desafios teórico-práticos (pp. 143-169). São Paulo: Casa do Psicólogo.

Machado, A. M. (2004). Relato de uma intervenção na escola pública. Em A. M. Machado \& P. R. Souza (Orgs.), Psicologia escolar: em busca de novos rumos (pp. 87-100). São Paulo: Casa do Psicólogo.

Marçal, V. P. B., \& Silva, S. M. C. (2006). A queixa escolar nos ambulatórios públicos de saúde mental: práticas e concepções. Psicologia Escolar e Educacional, 10(1), 121-131.

Meira, M. E. (2000). Psicologia escolar: pensamento crítico e práticas profissionais. Em E. Tanamachi, M. Proença \& M. Rocha (Org.), Psicologia e educação: desafios teórico-práticos (pp. 3572). São Paulo: Casa do Psicólogo.

Neves, M. M. B. J., \& Marinho-Araújo, C. M. (2006). A questão das dificuldades de aprendizagem e 0 atendimento psicológico às queixas escolares. Alethéia, (24), 161-170.

Patto, M. H. S. (1997a). A família pobre e a escola pública: anotações sobre um desencontro. Em M. H. S. Patto (Org.), Introdução à psicologia escolar (3. ed., pp. 281-298). São Paulo: Casa do Psicólogo.
Patto, M. H. S. (1997b). O papel social e a formação do psicólogo: contribuição para um debate necessário. Em M. H. S. Patto (Org.), Introdução à psicologia escolar (3. ed., pp. 459-468). São Paulo: Casa do Psicólogo.

Patto, M. H. S. (2005). Violência nas escolas ou violência das escolas? Em M. H. S. Patto (Org.), Exercícios de Indignação: Escritos de Educação e Psicologia (pp. 29-40). São Paulo: Casa do Psicólogo, 2005.

Proença, M. (2000). A queixa escolar na formação de psicólogos. Em E. Tanamachi, M. Proença \& M. Rocha (Org.), Psicologia e educação: desafios teórico-práticos (pp. 105-137). São Paulo: Casa do Psicólogo, 2000.

Sayão, Y., \& Guarido, R. L. (2004). Intervenção psicológica em creche/pré-escola. Em A. M. Machado \& M. P. R. SOUZA (Orgs.), Psicologia Escolar: em busca de novos rumos (pp. 83-91). São Paulo: Casa do Psicólogo.

Souza, M. P. R. (2006). Políticas públicas e educação: desafios, dilemas e possibilidades. Em L. S. Viégas \& C. B. Angelucci (Orgs.), Políticas Públicas em Educação: uma análise a partir da Psicologia Escolar (pp. 229-243). São Paulo: Casa do Psicólogo.

Souza, M. P. R. (1996). A queixa escolar e a formação do psicólogo. Tese de Doutorado, Instituto de Psicologia, Universidade de São Paulo, São Paulo.

Souza, M. P. R. (1997). A queixa escolar e o predomínio de uma visão de mundo. Em A. M. Machado \& M. P. R. Souza (Orgs.), Psicologia escolar: em busca de novos rumos (pp. 19-37). São Paulo: Casa do Psicólogo.

Souza, M. P. R. (2006). Políticas públicas e educação: desafios, dilemas e possibilidades. In.: Viégas, L. S. e Angelucci, C. B. Políticas Públicas em Educação: uma análise a partir da Psicologia Escolar. São Paulo: Casa do Psicólogo.

Souza, M. P. R. (2007). Prontuários revelando os bastidores do atendimento psicológico à queixa escolar. Em B. P. Souza (Org.), Orientação à queixa escolar (pp. 27-58). São Paulo: Casa do Psicólogo.

Tanamachi, E. (2000). Mediações teórico-práticas de uma visão crítica em psicologia escolar. Em E. Tanamachi, M. Proença \& M. Rocha (Org.), Psicologia e educação: desafios teórico-práticos (pp. 73-103). São Paulo: Casa do Psicólogo, 2000.

Recebido em: 01/10/2007

Revisado em: 05/11/2008

Aprovado em: 12/11/2008

\section{Sobre as autoras}

Mariana Sathie Nakamura (mari.sathie@gmail.com) - acadêmica do 6ํperíodo do Curso de Psicologia da Universidade Federal de Rondônia, bolsista do CNPq.

Vanessa Aparecida Alves de Lima (limavanessa@uol.com.br) - Doutora em Psicologia Escolar e do Desenvolvimento Humano IP/USP e Docentes do Departamento de Psicologia da Universidade Federal de Rondônia

Iracema Neno Cecilio Tada (iracematada@hotmail.com) - Doutora em Psicologia Escolar e do Desenvolvimento Humano IP/USP e Docentes do Departamento de Psicologia da Universidade Federal de Rondônia

Maria Hercília Rodrigues Junqueira (hercilia@unir.br) - Doutora em Psicologia Escolar e do Desenvolvimento Humano IP/USP e Docentes do Departamento de Psicologia da Universidade Federal de Rondônia

Endereço para correspondência - Br 364 km 9,5. Campus Porto Velho. Departamento de Psicologia - Porto Velho - RO CEP: $78900-970$. 
